\title{
Mineração
}

\section{Diagnóstico dos processos de licenciamento e fiscalização das pedreiras de rochas ornamentais na região centro-sul de Minas Gerais}

\section{(Diagnosis of the licensing processes and fiscalization of the quarries of ornamental rocks region south center of Minas Gerais)}

\author{
Érika Silva Fabri \\ Mestranda em Geologia Ambiental - Departamento de Geologia (DEGEO) /Escola de Minas/UFOP \\ E-mail:erikafabri@degeo.ufop.br
}

Maurício Antônio Carneiro

Professor do Departamento de Geologia (DEGEO) /Escola de Minas/UFOP. E-mail: mauricio@degeo.ufop.br

Mariangela Garcia Praça Leite

Professora do Departamento de Geologia (DEGEO) /Escola de Minas/UFOP. E-mail: garcia@degeo.ufop.br

\section{Resumo}

Apresenta-se o diagnóstico da análise de 130 processos de licenciamento e fiscalização ambiental oriundos de 81 pedreiras de rochas ornamentais, localizadas em cinco municípios da região centro-sul de Minas Gerais (Campo Belo, Candeias, Oliveira, São Francisco de Paula, Cláudio). Tais processos estão arquivados na Fundação Estadual do Meio Ambiente de Minas Gerais FEAM. Da análise desses processos, juntamente com as visitas ao campo, constatou-se o desrespeito dos empreendedores aos autos de infração e às medidas mitigadoras propostas e exigidas pela FEAM. Conseqüentemente, muitos processos são arquivados ou ficam pendentes. O resultado mais visível desse imbróglio é que, na região em análise, nenhuma área de extração de rochas ornamentais foi submetida a processo de recuperação ambiental, evidenciando a externalização de impactos e correspondentes custos sociais para desconforto da população da região. Os efeitos recentes da atividade de extração de rochas ornamentais tornam-se ainda mais severos na medida em que, sobretudo nos municípios de Candeias e São Francisco de Paula, diversas áreas foram paralisadas por razões de mercado, com conseqüente redução da oferta de trabalho para a população local.

Palavras-chave: Mineração, rochas ornamentais, legislação ambiental, economia mineral e política mineral.

\begin{abstract}
The diagnosis of the analysis of 130 environmental licensing and fiscalization processes regarding 81 ornamental stone quarries, located in five municipalities of the central-southern region of Minas Gerais State (Campo Belo, Candeias, Oliveira, São Francisco de Paula and Cláudio) is presented. These processes have been filed in the Minas Gerais Statal Foundation for the Environment - FEAM (Fundação Estadual do Meio Ambiente de Minas Gerais). The analysis of the processes, coupled with field work, revealed the lack of respect of the enterprises toward the infraction proceedings and mitigating measures proposed and required by FEAM. Consequently, several processes have been filed or pigeon-holed. The most visible result of such obstacle is that there has not been a single area of ornamental stone extraction in the study region under environmental recovery, which has been causing social impacts and costs. The recent effects of such extraction activies are even worse, specially in Candeias and São Francisco de Paula, because in several areas mining was paralized due to market and job decreases.
\end{abstract}

Keywords: Mining, ornamental rock, environmental legislation, mineral economy, mineral politics. 
Diagnóstico dos processos de licenciamento e fiscalização das pedreiras de rochas ornamentais...

\section{Introdução}

A extração mineral é considerada um dos setores básicos da economia de uma região e contribui para o bem-estar e melhoria de vida da população. Porém é fundamental a observância dos aspectos relacionados à responsabilidade social, sempre considerando os preceitos do desenvolvimento sustentável (Farias, 2002). No Brasil, o instrumento fundamental da legislação mineral é o Código de Mineração, Decreto lei n ${ }^{\circ} 27 / 67$, cuja aplicação é atribuída ao Departamento Nacional de Produção Mineral - DNPM. Segundo esse código, seis são os regimes de enquadramento das atividades, a saber: 1) regime de concessão; 2) de autorização; 3 ) de licenciamento (onde o poder concedente é municipal); 4) de permissão de lavra garimpeira; 5) de monopolização e 6) de extração (exclusivo para órgãos da administração). Segundo IPT (2005), no caso da extração de rochas ornamentais, os regimes de aproveitamento são os de autorização/concessão e de licenciamento. Em particular, no Estado de Minas Gerais, é o Decreto 44.309/06 que trata do Licenciamento Ambiental e da Autorização Ambiental de Funcionamento. Por lei, o Licenciamento Ambiental e a Autorização Ambiental de Funcionamento são executados pelo COPAM (Conselho Estadual de Política Ambiental), por intermédio das Câmaras Especializadas, das Unidades Regionais Colegiadas (URCs), das Superintendências Regionais de Meio Ambiente e Desenvolvimento Sustentável (Suprams), da FEAM (Fundação Estadual do Meio Ambiente) e do IEF (Instituto Estadual de Florestas).

De acordo com a FEAM, o processo de licenciamento ambiental possui três etapas: a Licença Prévia (LP, a ser concedida na fase preliminar da atividade); a Licença de Instalação (LI, a ser concedida na fase de implantação do empreendimento, com o detalhamento de projetos, obras de engenharia e processos de controle ambiental a serem utilizados); a licença de Operação (LO, que autoriza o início de qualquer atividade ou equipamento potencialmente poluidor).
Teoricamente, a fiscalização tem como finalidade subsidiar a análise do licenciamento ambiental (LP, LI, LO, Revalidação de LO), atender à denúncia, acompanhar passivo ambiental, acompanhar condicionante e pós-licenciamento, atender à emergência ambiental, verificar empreendimentos com Autorização Ambiental de Funcionamento (AAF), atender ao Ministério Público/Poder Judiciário. Durante as fiscalizações, é obrigatoriamente gerado o Auto de Fiscalização (AF) e, se constatada alguma irregularidade, é lavrado o Auto de Infração (AI). Os tipos de penalidades previstas para infração à legislação ambiental são: advertência, multa, apreensão dos animais, produtos e subprodutos da fauna e flora, instrumentos, equipamentos ou veículos de qualquer natureza utilizados na infração, destruição ou não utilização do produto, suspensão de venda e fabricação do produto, embargo de obra ou atividade, demolição de obra, suspensão parcial ou total das atividades restritiva de direitos.

\subsection{Objetivos}

O objetivo desse estudo foi avaliar a eficiência da legislação ambiental e fiscalização nos empreendimentos mineiros de extração de rocha ornamental em cinco municípios mineiros. Como objetivo específico, procurou-se analisar todos os processos de licenciamento, dos empreendimentos de extração mineral nesses municípios, qual a freqüência de fiscalização, o grau de cumprimento das exigências legais feitas pela FEAM aos empreendimentos, cadastrar as empresas com maior número de irregularidades em cada município e avaliar até onde as exigências legais estão sendo cumpridas, tanto por parte dos empreendedores, quanto por parte da própria FEAM.

\section{2 Área de estudo}

A área de estudo compreende cinco municípios da região centro-sul do Estado de Minas Gerais, a saber: Campo Belo, Candeias, Oliveira, São Francisco de Paula e Cláudio (Figura 1). O substra- to rochoso dessa região pertence ao Complexo Metamórfico de Campo Belo e os litotipos mais comuns são gnaisses e granitóides de idade arqueana (Carneiro et al., 2006). A maior incidência de pedreiras, para extração de rocha ornamental, está implantada nas rochas gnáissicas de composição granítica e granodiorítica. Esses litotipos foram denominados por Oliveira et al. (2001) de Gnaisse Candeias (comercialmente chamado “Granito Verde Candeias") e Gnaisse Itapecerica (variedade Knawa).

A atividade de extração de rochas ornamentais nesses municípios teve início na década de sessenta, alcançando seu ápice vinte anos depois, abastecendo os mercados interno e externo. Mudanças, principalmente no mercado externo, durante os anos 90 e no começo do século XXI, reduziram a demanda pelas rochas ornamentais dessa região. A principal razão foi a volatilidade da demanda comercial dessa atividade, vinculada a modismos ou novidades, relacionadas às novas cores e/ou texturas rochosas mais exóticas. Com isso, nos últimos quinze anos, a maioria dos empreendimentos foi abandonada.

A comercialização de rochas ornamentais está freqüentemente sujeita a tais descontinuidades de mercado, sob efeito de novas tendências, em termos de moda, ornamentação e padrões construtivos. Portanto, as diretrizes de Política Mineral e de Gestão Ambiental devem incorporar essa perspectiva de paralização de empreendimentos de extração de rochas ornamentais, devendo estabelecer as necessárias salvaguardas de interesse da sociedade, mediante exigências de progressiva recuperação ambiental da área minerada, bem como de gradativa formação de garantias financeiras para fazer face às correspondentes despesas.

\section{Materiais e métodos}

Metodologicamente, o estudo foi conduzido sob dois aspectos. O primeiro está relacionado à investigação de campo, com a visita à área de estudo, coleta de dados e descrição minuciosa 


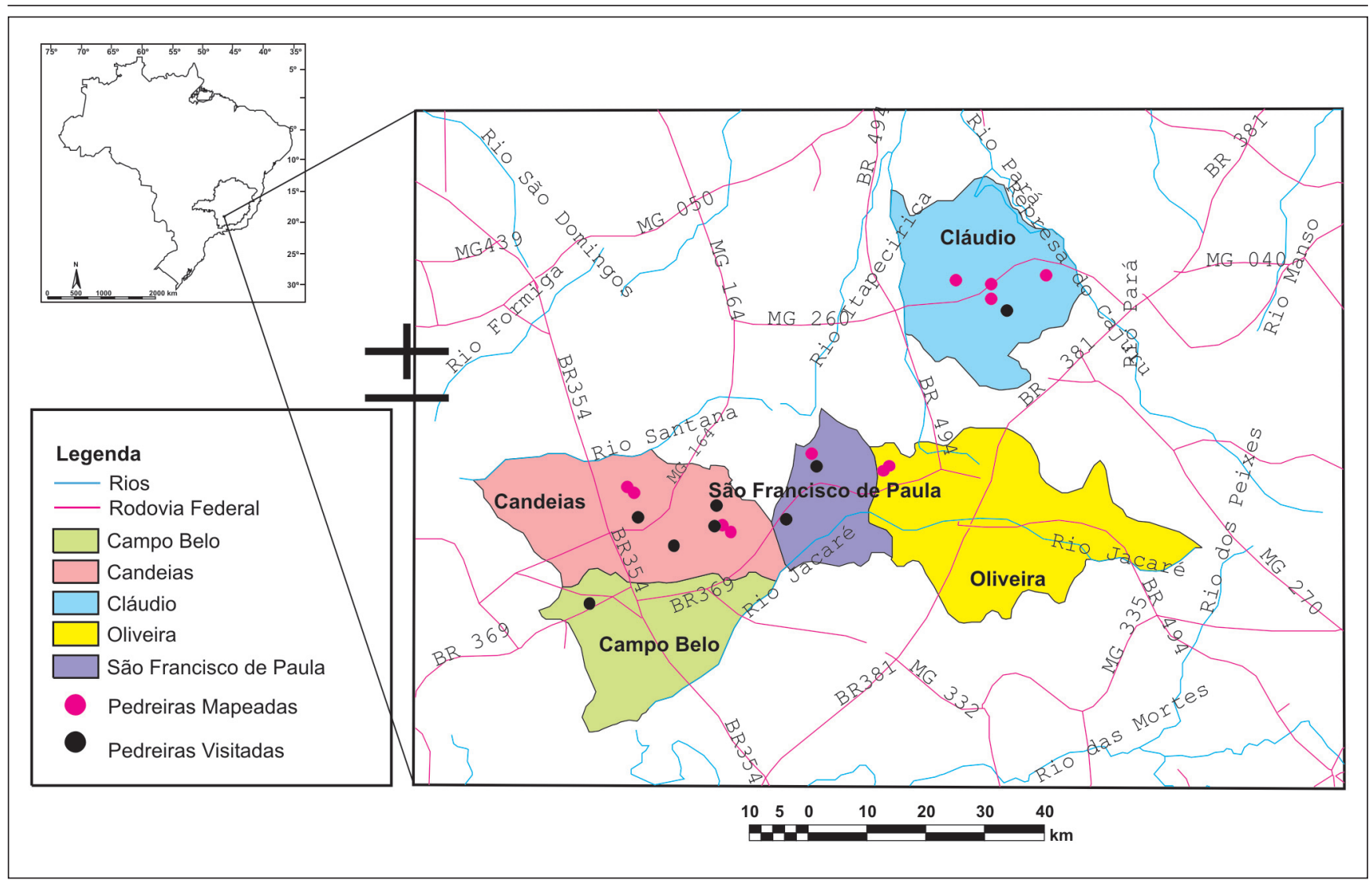

Figura 1 - Localização dos municípios investigados nesse trabalho.

das atividades desenvolvidas pela mineração de rochas ornamentais na região. Concomitantemente, investigou-se a presença de fiscais - especialmente da FEAM-, nas áreas onde a atividade de extração mineral está inoperante ou foi descartada pelas mineradoras. Paralelamente, realizou-se uma pesquisa sócioeconômico-ambiental com ex-funcionários dessas empresas. Foram entrevistadas 62 pessoas, sendo 4 em Campo Belo, 21 em Candeias, 17 em São Francisco de Paula, 9 em Oliveira e 11 em Cláudio. O segundo aspecto está relacionado à pesquisa dos processos registrados na FEAM. Para isso foi requerida, junto a essa fundação, uma lista dos empreendimentos de extração mineral dos municípios estudados. Dos documentos recuperados, verificaram-se as seguintes classes de processos: 1) licença para pesquisa mineral; 2) licença prévia; 3) licença de instalação; 4) licença de operação; $5)$ autos de infração. Após essas classes de processos terem sido requisitadas à FEAM, e analisados nas dependências dessa instituição, algumas partes de cada processo foram fotocopiadas para análise mais detalhada do processo de licenciamento das pedreiras a posteriori. É importante salientar que os processos são constituídos por documentos particulares das empresas como, por exemplo, plano de controle ambiental, autos de infração e defesa dos autos de infração e que, portanto, não podem ser copiados sem a devida autorização do proprietário.

\section{Discussão}

No decorrer da etapa de campo ficou constatado que os principais problemas desse tipo de extração mineral são: a perturbação da superfície, remoção da vegetação com perda do banco de sementes e da biota, remoção do solo, geração e disposição inadequada dos rejeitos em áreas de bota-fora, abertura de estradas mal planejadas, imposição de superfícies diferentes do relevo original (eliminação de picos e serras), degrada- ção do entorno, principalmente em áreas de empréstimos de solos, liberação de poeira e a geração de poluição sonora. Pode-se dizer que a maior característica desta atividade mineradora é, realmente, o grande impacto sobre o meio físico. Da exploração resulta a produção de um grande volume de rejeito (material estéril retirado, lascas e blocos quebrados durante a exploração), cuja disposição constitui um dos mais sérios desafios.

Já a pesquisa realizada nos arquivos da FEAM revelou que a região estudada dispõe de 163 processos envolvendo minerações de rochas ornamentais (Tabela 1). No entanto, desses 163 processos, somente 130 (Tabela 2) foram disponibilizados pela FEAM. Os demais se enquandram numa das seguintes situações: 1) processos em tramitação interna em algum departamento da Fundação; 2) processos depositados em outras regionais (e.g. Divinópolis); 3) processos na AGE (Advocacia Geral do Estado - Dívida Ativa - como multa não 
Diagnóstico dos processos de licenciamento e fiscalização das pedreiras de rochas ornamentais...

paga); 4) processos em tramitação interna sem referência de setor; 5) processos perdidos na própria FEAM.

A análise dos processos revelou que, aproximadamente, $60 \%$ das empresas começaram suas atividades de extração mineral depois que o empreendimento estava legalizado junto à FEAM. Porém $40 \%$ das empresas, antes de ter o pedido de licenciamento (LI e LO) aprovado pela FEAM, já se encontravam em pleno funcionamento. Mesmo assim, nem todas foram multadas pela FEAM, quando da vistoria para a concessão das licenças solicitadas. A práxis do processo é ter a concessão da licença e, concomitantemente, apresentar as medidas mitigadoras dos impactos ambientais. No entanto, não há registro na FEAM de que essas mesmas áreas ainda continuam em funcionamento e muito menos se as medidas mitigadoras foram implantadas, ou seja, nenhuma vistoria foi realizada após a concessão das licenças.

Um exemplo disso é a empresa Mineração Mário Campos, localizada no município de São Francisco de Paula. Essa empresa encontrava-se instalada em 1988, em desacordo com a legislação ambiental vigente. Em 1989, solicitou a licença de funcionamento e, quando da vistoria pela FEAM, foi multada e dela exigido um plano de controle e recuperação ambiental. Após a análise do referido plano, a FEAM concedeu a licença de funcionamento. No entanto, quando da realização da etapa de campo da pesquisa, verificou-se que a pedreira se encontra inativa, há alguns anos, segundo moradores da região.

Outro caso é o da Mineração Bracon, localizada na Fazenda Areão Palmital - distrito de Corumbá - município de Cláudio. Essa empresa entrou com o processo de licença de operação para pesquisa mineral (LOP) junto à FEAM em 2005. Apos a vistoria da FEAM foi exigido que, para sua operação, seriam necessárias obras de drenagem da área de trabalho, bem como do depósito de estéril. Se cumpridas, e vistoriadas, a FEAM autorizaria a exploração (lavra

Tabela 1 - Processos registrados na FEAM para empreendimentos envolvendo rochas ornamentais nos municípios estudados.

\begin{tabular}{c|c|c|c|c|c|c}
\hline MUNICÍPIO & LOP & LP & LI & LO & AI & TOTAL \\
\hline Campo Belo & 0 & 0 & 0 & 3 & 2 & 5 \\
\hline Candeias & 15 & 20 & 11 & 20 & 14 & 80 \\
\hline Oliveira & 4 & 1 & 1 & 5 & 9 & 20 \\
\hline São Francisco de Paula & 9 & 8 & 7 & 10 & 4 & 38 \\
\hline Cláudio & 4 & 1 & 1 & 5 & 9 & 20 \\
\hline TOTAL GERAL & $\mathbf{3 2}$ & $\mathbf{3 0}$ & $\mathbf{2 0}$ & $\mathbf{4 3}$ & $\mathbf{3 8}$ & $\mathbf{1 6 3}$ \\
\hline
\end{tabular}

Tabela 2 - Processos efetivamente analisados.

\begin{tabular}{c|c|c|c|c|c|c}
\hline MUNICÍPIO & LOP & LP & LI & LO & Al & TOTAL \\
\hline Campo Belo & 0 & 0 & 0 & 3 & 0 & 3 \\
\hline Candeias & 11 & 17 & 10 & 10 & 10 & 58 \\
\hline Oliveira & 4 & 1 & 0 & 4 & 8 & 17 \\
\hline São Francisco de Paula & 8 & 8 & 7 & 8 & 3 & 34 \\
\hline Cláudio & 4 & 1 & 1 & 5 & 7 & 18 \\
\hline TOTAL GERAL & $\mathbf{2 7}$ & $\mathbf{2 7}$ & $\mathbf{1 8}$ & $\mathbf{3 0}$ & $\mathbf{2 8}$ & $\mathbf{1 3 0}$ \\
\hline
\end{tabular}

propriamente dita) da pedreira. Em janeiro de 2006, em nova vistoria da FEAM, foram exigidas novas providências. Porém, a prefeitura de Cláudio declarou que o empreendimento e o local de sua instalação estão em desacordo com as leis e regulamentos aplicáveis ao uso e ocupação do solo, visto que existe uma nascente na localidade. Em fevereiro de 2006, o COPAM resolveu pela não concessão da LOP. No decorrer da visita de campo, constatou-se que nenhuma das providências exigidas pela FEAM foi realizada e que a atividade de extração está paralisada. Assim, sem previsão do retorno das atividades exploratórias a área continua degradada.

Aproximadamente 36\% dos AI (autos de infração) analisados tiveram suas multas pagas, $18 \%$ foram encaminhados para a Dívida Ativa e aproximadamente $46 \%$ se enquadram no que a FEAM cha- ma de prescrição/decadência, ou seja, a empresa opera com irregularidades na extração, é multada (com reincidência às vezes) e solicita reconsideração da multa. Geralmente, a análise desses processos é tão demorada que a FEAM considera o processo prescrito. Com isso, a empresa fica livre da multa e, ainda, tem tempo para corrigir as irregularidades e só será vistoriada após outra denúncia. Esse é o caso, por exemplo, da empresa Mineração Campo Belo. Essa empresa iniciou suas atividades em 1979. Por estar situada às margens da rodovia BR 369 - km 02, a sua volumosa emissão de particulados coloca em risco o trafego rodoviário na região. Em 1997, foi autuada pela emissão desse particulado. A multa foi aplicada, mas, por não ter sido quitada, o processo foi encaminhado à Advocacia Geral do Estado e arquivado como Dívida Ativa. Em 2000, a FEAM 
aplicou uma segunda multa, que, até o final de 2006, não havia sido quitada. $\mathrm{Na}$ visita de campo, realizada em novembro de 2006, constatou-se que a extração continua em funcionamento e o particulado emitido carece de qualquer controle ambiental, colocando em risco a saúde dos moradores da região e o tráfego na rodovia.

Há, também, empreendedores que, após uma denúncia e/ou um auto de infração, mudam a razão social da empresa para não quitar a multa e solicitam novo licenciamento sob a nova designação jurídica. Foi o que aconteceu, por exemplo, com a extração de granito na Fazenda Faleiro, localizada no município de Cláudio, que, em 1990, era explorada pela Mincoel - Mineração, Indústria, Comércio e Exportação Ltda. Essa empresa foi multada pela FEAM por instalar, dar início e prosseguir a atividade de exploração de granito com fonte de poluição, sem a obtenção das LI e LO, já que não apresentou o PRAD (Plano de Recuperação de Área Degradada). A empresa recorreu ao Auto de Infração que lhe foi aplicado, porém seu pedido de reconsideração foi indeferido. Aplicou-se a multa, que, até final de 2002, não havia sido quitada e, portanto, foi considerada a incidência de prescrição/decadência com o conseqüente arquivamento dos autos de infração. No entanto, em 1993 essa mesma área passou a ser explorada pela Eminosa Empresa de Mineração Ltda. Após essa data, não há mais registro na FEAM. Em 1993, foi a vez da Britas Pedra Verde Ltda. inciar a exploração da área. Essa empresa foi autuada duas vezes pela instalação e construção de atividade efetivamente poluidora ou degradadora do meio ambiente sem a obtenção da LI, que foi concedida posteriormente. No ano seguinte, o direito de exploração da área da Fazenda Faleiro foi vendido para a Belmont Ltda., porém as multas emitidas pela FEAM não tinham sido quitadas. Em 2003, considerou-se a incidência da prescrição/decadência dessas multas, com conseqüente arquivamento dos Autos de Infração.

\section{Conclusões e recomendações}

Os impactos ambientais provocados pelas atividades de mineração de rochas ornamentais, especialmente os gnaisses e granitos, são, em sua maioria, reversíveis. Mas, para isso, é necessário que todos os atores envolvidos participem do processo de recuperação. Assim, é fundamental que a sociedade, as empresas e o poder público façam sua parte. Um dos maiores empecilhos no cumprimento real da legislação ambiental é a sua extensão. Outras vezes, ela é incompreensível, tanto para os empreendedores, quanto para fiscalizadores. Tudo isso dificulta a sua aplicação. Relativamente à pesquisa realizada nos processos arquivados na FEAM, constatouse o desrespeito dos empreendedores aos autos de infrações e às medidas mitigadoras propostas. As multas são remetidas para a Dívida Ativa e, muitas delas, jamais serão quitadas. Assim como as medidas mitigadoras, não são executadas. O resultado desse quadro é que nenhuma área, investigada nessa pesquisa, foi recuperada. Finalmente, nas entrevistas realizadas com ex-trabalhadores dessas pedreiras, constatou-se o seguinte: 1) que o exército, o IBAMA, o IEF e a FEAM realizam visitas de fiscalização. Dessas entidades, porém, o exército é o mais presente por causa dos explosivos usados para extração das rochas; 2) que o surgimento das pedreiras de rochas ornamentais, além de criar inúmeros empregos, promoveu um aumento significativo da população local; 3) que a paralisação e, posterior abandono das explotações afetaram a economia dos municípios e os mais afetados foram Candeias e São Francisco de Paula, por dependerem quase que exclusivamente dessa atividade. A mesma situação não ocorreu, por exemplo, nos municípios de Campo Belo, Cláudio e Oliveira, onde o número de pedreiras era menor e a economia desses municípios era mais diversificada.
Diante do exposto, sugere-se a adoção de um plano de lavra mais compatível, bem como a produção de blocos menores para processamento em talhablocos, visando à redução da geração de rejeitos na lavra. Além disso, recomenda-se que, para menor dependência do mercado de exportação e maior produção de blocos, é necessária a verticalização da cadeia produtiva, tanto local, quanto regional, de forma a possibilitar a agregação de valor e a geração mais intensa de postos de trabalho.

\section{Referências bibliográficas}

BRASIL. Decreto 44.309/06 - 05 de junho de 2006. Estabelece normas para o licenciamento ambiental e a autorização ambiental de funcionamento, tipifica e classifica as infrações às normas de proteção ao meio ambiente e aos recursos hídricos e estabelece o procedimento administrativo de fiscalização e aplicação das penalidades.

BRASIL. Resolução do CONAMA 001 - 23 de janeiro de 1986. Estabelece as definições, as responsabilidades, os critérios básicos e as diretrizes gerais para uso e implementação da Avaliação de Impacto Ambiental como um dos instrumentos da Política Nacional do Meio Ambiente.

CARNEIRO, M.A., ENDO, I., NALINI, Jr. H.A., SALES, J.C.C., GOULART, L.E.A., SILVA, E.F., PEREIRA, A.A., TAVARES, T.D., JIAMELARO, F., CARNEIRO, J.M., MARIANO, L.C., PRADO, G.E.A., URBANO, E.P.C., SANTOS, C., MIGUEL F.P. Folhas Campo Belo e Oliveira (1:100.000). Convênio CPRM/UFOP. 192p. 2006.

CHAVES, A. P., JOHNSON, B., FERNANDES, F., SIROTHEAU, G. J. C., LIMA, M. H. R., BARRETO, M. L., VILLAS BÔAS, R. C., NAHASS, S. Mineração e desenvolvimento sustentável: desafios para o Brasil. CETEM/MCT, Maria Laura Barreto Editor, 2001. 215p.

DRM.RJ 2002 - ASPECTOS LEGAIS DA MINERAÇÃO DE ROCHAS ORNAMENTAIS. Informação capturada de http://www.drm.rj.gov.br/ aspectos.htm. Departamento de Recursos Minerais - Rio de Janeiro (DRM.RJ). 
Diagnóstico dos processos de licenciamento e fiscalização das pedreiras de rochas ornamentais...

FARIAS, C.E.G. Mineração e meio ambiente no Brasil, PNUD - Contrato 2002/001604. Centro de Gestão e Estudos Estratégicos. Ciência, Tecnologia e Inovação. CGEE. 2002. 42p.

FEAM. Fiscalização, regularização ambiental e licenciamento. Informação capturada de http://www.feam.br. Fundação Estadual do Meio Ambiente (FEAM)

IPT - Instituto de Pesquisa Tecnológica do Estado de São Paulo, 2005. Minerais industriais: orientação para regularização e implantação de empreendimentos/coordenadores Marsis Cabral Junior, Oswaldo Riuma Obata, Ayrton Sintoni. (Publicação IPT: 3000). 350p., cap. 5 - Bases Legais para Implantação de Empreendimentos, p. 47 a 55. São Paulo: 2005.

MINTER, Instituto Brasileiro do Meio Ambiente e dos Recursos Naturais Renováveis. Manual de recuperação de áreas degradadas pela mineração: técnicas de revegetação/ IBAMA. Brasília: 1990. 96p., cap. 3 - Legislação Federal Existente, p. 15.

OLIVEIRA, A.H., CARNEIRO, M.A. Campo Belo metamorphic complex: tectonic evolution of na archean sialic crust of the southern São Francisco Cráton in Minas Gerais (Brazil). An. Acad. Bras. Cienc., 73, p. 397-415. 2001.

RIPLEY, E.A., REDMANN, R.E., CROWDER, A.A. Environmental effects of mining. Florida: St. Lucie Press, Delray Beach, 1996. 356p.

Artigo recebido em 20/06/2007 e aprovado em 07/04/2008. 